ISSN: 2224-0616

Int. J. Agril. Res. Innov. \&Tech. 6 (2): 77-81, December, 2016 Available online at http://www.jjarit.webs.com

\title{
HOW THE TIMING AND LOCATION OF VIDEO SHOWS INFLUENCE LEARNING AMONG RICE FARMERS IN UGANDA
}

\section{Gabriel Karubanga1*, Paul Kibwika1, Florent Okry2,3 and Haroon Sseguya4}

Received 19 October 2016, Revised 13 December 2016, Accepted 27 December 2016, Published online 31 December 2016

\begin{abstract}
Videos have the potential of enhancing learning among smallholder farmers. The study intended to establish whether timing and location of video shows influence learning among rice farmers in Kamwenge district, Uganda. A cross-sectional study was conducted by interviewing 48 focus group participants; 100 individual video participants and 16 key informants. Geographical Positioning System (GPS) mapping was used to establish the video catchment areas and distribution of video participants. Farmers approved the video for providing timely, useful and reliable information and bringing extension service providers closer to the farming communities. Majority (94\%) of the farmers said that video provided useful information that fostered change in rice production practices and technologies. A one sample T-test indicated that the timing and location of video events are significant in influencing learning among farmers particularly by women, elderly and distant farmers. The implication is that locating video shows far away and running them late at night seriously compromised involvement by females, elderly and distant people. Thus, modalities suggested by farmers need to focus on adjusting the timing of video shows and ensuring rotational operational of videos in the respective villages or parishes purposely to reach out to the elderly, distant and women farmers.
\end{abstract}

Keywords: ICTs, Video-Mediated Extension Approach, Smallholder Farmer, Learning, Uganda

${ }^{1}$ Department of Extension and Innovation Studies, College of Agricultural and Environmental Sciences, Makerere University, P.O. Box. 7062, Kampala, Uganda

${ }^{2}$ University of Agriculture of Ketou, BP 13, Ketou, Rep. of Benin

${ }^{3}$ Access Agriculture, 04. BP 282 Cotonou, Rep. of Benin

${ }^{4}$ International Institute of Agriculture, Regional Hub for Eastern Africa P.O Box 34441 Dar es Salaam, Tanzania.

*Corresponding author's email: gkarubanga@caes.mak.ac.ug; amootigabs@gmail.com (Gabriel Karubanga)

\section{Introduction}

Information and Communication Technologies (ICTs) are gaining prominence in dissemination of agricultural information, videos being one of such tools (David and Asamoah, 2011; Bentley and Van Mele, 2011). Today radios, televisions (TVs), videos and telephones are playing a pivotal role in addressing the extension related challenges allied to access to agricultural information (UBOS, 2010; Van Mele et al., 2010; Zossou et al., 2010). In particular, effective use of video need to be considered in as far as it can stimulate learning among farmers (MacGregor, 2007). Video creates awareness and sharing of high-quality information with a large audience (Bentley et al., 2013); however, the logistical factors such as timing and location of video shows that are likely to influence its effectiveness are not clearly explained. Learning among farmers is seen as a continuous experience sharing requiring proper approaches that can enhance it more sustainably (Danielsen et al., 2015).

Since 2005, Africa Rice has been recording farmers with innovative practices and using the videos to disseminate and share experiences and knowledge on better rice production practices (Bentley and Van Mele, 2011; Bentley et al.,
2013). In Uganda, Sasakawa Global 2000 (SG 2000), a Non-Government Organization (NGO) piloted use of video-mediated extension approach (VMEA) in Kamwenge district for about three years (2007-2010) and it is said to be one of the successful cases where farmers had access to agricultural information and have continued to learn from each other even without SG 2000. However, the logistical factors such as timing and location of video shows that influence learning among rice farmers through videos are not yet clearly known, the issue of investigation in this paper. Earlier studies in Uganda and elsewhere focused on assessment of effectiveness of video in disseminating agricultural knowledge to farmers (Van Mele et al., 2010; Tumwekwase, 2013) with limited attention on how the timing and location of video shows influence its effectiveness in fostering learning among farmers. Yet, timing and distance are key determinants of access and learning (Danielsen and Kelly, 2010). As there are new directions towards use of ICTs particularly video to disseminate agricultural information in Uganda (Van Mele, 2011), there is need to assess whether the timing and location of video shows have an influence on learning among farmers. 
The study therefore sought to establish the influence of timing and location of video shows on learning among rice farmers in Kamwenge district, Uganda using the case of SG 2000 rice videos. In this study, learning is defined as the ability of the farmers to attend, watch, acquire information and later discuss it among them. The video participants are the farmers who attend, view and learn about rice production practices and technologies through video.

\section{Materials and Methods}

The study was conducted in Mahyoro sub-county in Kamwenge district, Uganda in which SG 2000 videos for knowledge dissemination on rice for three years (2007 to 2010) were implemented. The study was conducted from August 2015 to February 2016. Eight villages in Mahyoro subcounty were purposively selected because records of farmers who participated existed. The study employed both qualitative and quantitative approaches to assess how the timing and location of video shows influenced learning among rice farmers in Mahyoro sub-county of Kamwenge district in Uganda. The qualitative approach involving focus group discussions (FGDs) was employed to gain deeper understanding of how the timing and location of video shows influenced learning among rice farmers. Quantitative approach involving a cross-sectional survey was used to generate percentages on the sociodemographic features of respondents and inferential statistics about farmers' opinions on the timing and location of video shows.

All the 100 video participants whose records were available were selected for the survey that involved administration of a semi-structured questionnaire. Out of these, 71 were males and 29 were females. Forty-eight video participants including 19 males and 29 females were purposively selected based on their experience in rice production and regularity in attending the video shows. Focus group participants were selected by taking at least eight participants from each of the three villages of Karere, Kyendangara and Kitomi, which had higher number of 36-50 video participants. Limiting the number to eight allowed for focused discussions among the participants to gain a deeper understanding of how the timing and location of video shows influenced farmers' learning. Other villages such as Rwentuma, Buhindagi, Kitonzi, Katanga and Burembo registered low attendance of 1-2 video participants. The participants from these five villages with low number of participants were purposively selected and combined to form one FGD. Key informant interviews with 16 interviewees were also conducted to generate deeper insights about their opinion about the timing and location of video operations.

Qualitative data generated through focus group and key informant interviews were processed through coding and content analysis by extracting and relating information on the timing and location of video shows. Qualitative data analysis started while in the field during data collection process to minimize the loss of meaning of respondents' explanations on the influence of the timing and location of video shows. Quantitative data on video participants' opinions on the influence of timing and location of video shows were analyzed using SPSS 18.0 version to generate descriptive statistics (percentages) and inferential statistics (One sample T-tests). Quotes from the respondents are used to support their narrative explanations. Geographical positioning system (GPS) coordinates were entered into AroGIS version 10.1 software to generate a map for the video catchment area and distribution of participants.

\section{Results and Discussion}

Socio-demographic characteristics of respondents in Table 1 summaries the profile of rice farmers exposed to VMEA.

Table 1. Socio-demographic characteristics of video participants.

\begin{tabular}{lc}
\hline Variable & VMEA (n=100) \% \\
\hline Gender & 71 \\
Males & 29 \\
Females & 25 \\
Age & 54 \\
Below 30 years & 21 \\
Between 31-50 years & \\
Above 50 years & 89 \\
Level of education & 11 \\
No formal education & \\
Formal education (not beyond primary) & 98 \\
Major occupation of respondents & 2 \\
Farmer & 2 \\
Personal business & \\
\hline
\end{tabular}

Source: Household survey 2015

The sample comprised of more males who attended and learnt from the video shows than females. Most of farmers who participated in the video shows were in the middle age category of
31-50 years. It is however important to note that more youth (below 31 years) attended the video shows possibly due to the entertainment element embedded in the video. 
The distance however coupled with the timing of the video can be a constraint to the female farmers because of their multiple gender responsibilities (Van Mele et al., 2007; Karubanga et al., 2016). The diversity of farmers attending and learning from video was exhibited in terms of membership to groups and age mix. This diversity is important in farmer learning as affirmed by Karubanga et al. (2016). Nearly all farmers (98\%) who attended and learnt from the video shows had no other off-farm activities. This is because the video attracts people at random. This is better explained by the location of Mahyoro sub-county in Kamwenge district which is surrounded by Queen Elizabeth National Park denying farmers the opportunity for off-farm activities.

\section{Influence of timing of video shows on farmer learning}

Majority (94\%) of the farmers approved the video for providing useful information that fostered change in rice production practices and technologies. The video participants reported that the video shows normally started at 7:30 pm and ended at 10:00pm during which all the twelverice production practices and technologies would be shown. However, the timing of video shows did not favour participation and learning by some segments of farmers. A one samples t-test indicates that the timing of video shows was statistically significant in influencing learning among rice farmers at $1 \%$ level of significance $(\mathrm{t}=58.186, \mathrm{p}<0.05)$. Thus, commencing and ending the video shows late at night did not provide an opportunity for participants to immediately share their knowledge and experiences on what they had learnt. The influence of learning from the videos would have been even more if there was time for farmers to discuss and exchange knowledge immediately after the video shows. However, the videos ended late $(10.00 \mathrm{pm})$ and at this time, every one rushed to get to their homes. In this regard, a female farmer in Burembo village said; "it would have been more beneficial if farmers discussed immediately after the video show because at that time the messages are still fresh in their mind and can easily relate what they saw and their own practices". Absence of joint reflection and sharing of information implied that farmers could not compare their experience of the video for common understanding of the messages communicated. The real learning, however, does not take place during the video shows but thereafter when farmers reflect on what they saw and evaluate it in their own context and start to experiment. This is typical of social learning processes (MacGregor, 2007; Danielsen et al., 2015).
Thus, if video shows are followed up with activities such as demonstrations, field days and exchange tours that facilitate farmer interaction and exchange of knowledge, the effectiveness of videos in behavioral change can be greatly enhanced. In particular, the timing, however, seems to have disfavoured females because this is the time when they are busy performing other domestic chores such as taking care of children and cooking; and this largely explains their low attendance (29\%) compared to males (71\%) as affirmed by Karubanga et al. (2016). Similarly, the elderly farmers and those from distant places were equally disfavoured by this timing. The video participants suggested that the video shows could start at midday to allow for women, elderly and distant farmers to participate and provide time for joint reflection and sharing.

\section{Influence of location of video shows on farmer learning}

Majority (81\%) of the video participants perceived the designated location of video shows to be appropriate because it was located at MARFA office (indicated in figure 1) where farmers frequently gathered for meetings. This clearly explains why the location of video shows was statistically significant in influencing easy access and learning among farmers at $1 \%$ level of significance $(t=26.098, p<0.05)$. For example, about (53\%) of farmers who attended and learnt from the video shows travelled one kilometer or more to the venue of the video shows. This illustrates the power of video in attracting farmers including those from far to get exposed to the information and knowledge as affirmed by Bede Lauréano (2016) and Karubanga et al. (2016). On the contrary, some farmers especially those from Burembo, Rwetuma and Katanga villages whose homes are located far away from MARFA offices expressed dissatisfaction with the centralization of the venue. They argued that having video shows fixed at MARFA office favoured only nearby individuals as indicated by high concentration of video participants (denoted by dots) in figure 1.

Video participants especially females, elderly and distant ones recommended that video shows should be rotated across villages or parishes. According to them, this would enhance accessibility of the video shows by providing equal opportunities for farmers from distant locations to also watch and learn from the video without walking long distances. Conversations with the SG 2000 extension worker revealed that rotating the videos would not be possible because of the financial constraints. Bentley et al. (2015) confirm our findings where they found out that rural woman in Bangladesh were discouraged from leaving their homes or villages or making 
trips to the markets located far away from them. However, our finding disagrees with those of Van Mele (2011) in Bangladesh where he found out that agricultural training videos had significant impact by reaching out and enhancing learning by more women $(54 \%)$ than men $(46 \%)$ because they were operated in villages where women resided. In other words, Van Mele (2011) finding confirm what the farmers from Kamwenge district suggested to rotate the video shows in their respective villages or parishes to enhance easy access and learning by marginalized groups such as females and the elderly farmers.

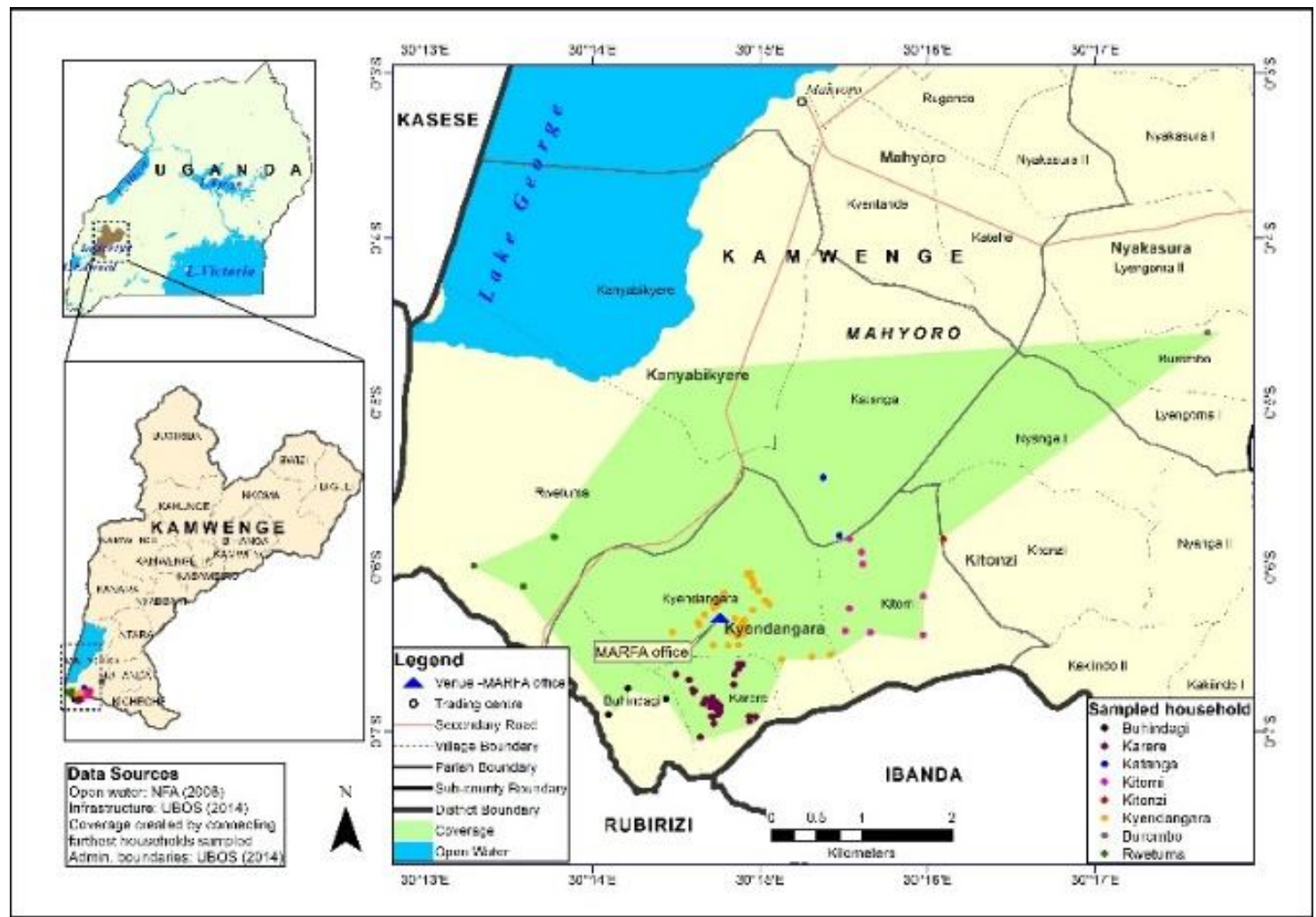

Fig. 1. Video catchment areas and distribution of participants in Mahyoro sub-county, Kamwenge district of Uganda.

\section{Conclusion}

The timing of video shows to start and end late at night was an assumption made by SG 2000 staff that all farmers would attend, watch and learn from the centrally located video shows. Surprising, more males were being favoured by the location and timing of video shows limiting attendance of females and distant individuals. Thus, the timing and location of video shows are significant in creating a selection bias about who attended and learnt from the video events. This means that the practitioners need to be conscious about when and where to show the videos if equitable access and learning is to be ensured. In other words, the timing and location of video shows did not only affect access to information by video participants but also never provided opportune time for participants to discuss, reflect and share their experiences which are critical elements in enhancing farmer learning. Thus, commencing video shows early in the day would not only avail farmers an opportunity to attend but also provide them time to share experiences. However, this has some tradeoffs as rescheduling the video shows may deny chance for those who prefer attending the video shows at night especially males, youth and busy people. This calls for showing two videos, one for farmers who prefer daytime and the other for those preferring night hours. However, rotating video shows across villages and parishes, and showing videos twice in a day have serious financial implications. Finally, our findings provide insights for the extension workers on how effectively they should organize operate the video shows to ensure access and learning by all farmers. 


\section{Acknowledgements}

Great thanks to Mr. Aliguma Emmanuel for his active participation during data collection exercise. The research was funded by Video for Farmers' project implemented by Access Agriculture and funded by the Swiss Agency for Development and Cooperation [Project Number 7F-08378.01]. Support for this research was also made possible through a capacity building competitive grant training the next generation of scientists provided by Carnegie Cooperation of New York through the Regional Universities Forum for Capacity Building in Agriculture (RUFORUM). Intra-ACP mobility SHARE project is acknowledged for the mobility financial support. Finally, DAAD is acknowledged for providing tuition fees for my $\mathrm{PhD}$ study.

\section{References}

Bede Lauréano, E.B. 2016. Analysis of the power of images and languages on farmers learning through training videos in Mono and Couffo Departments, MSc Dissertation, University of Abomey-Calavi, Abomey Calavi, Benin Republic. pp. 40-55.

Bentley, J. and Van Mele, P. 2011. Sharing ideas between cultures with videos. Int. J. Agril. Sust. 9 (1): 25-263.

Bentley, J.W., Van Mele, P. and Musimami, G. 2013. The mud on their legs - Farmer -toFarmer Videos in Uganda', MEAS case study \#3, Michigan State University, Vol. 26.

Bentley, J.W., Van Mele, P., Harun-Ar-Rashid, M. and Krupnik, T.J. 2015. Distributing and Showing Farmer Learning Videos in Bangladesh. J. Agril. Edu. Ext. 21(1): 1-19.

Danielsen, S. and Kelly, P. 2010. A novel approach to quality assessment of plant health clinic. Int. J . Agril. Sust. 8: 4-6.

Danielsen, S. Karubanga, G. and Mulema. J. 2015. Institutionalization. Listening to the silent patient. Uganda's journey towards institutionalizing inclusive plant health services. CABI working paper 7. Doi.org/ 10.1079/CABIPLANT-37-55.
David, S. and Asamoah, C. 2011. Video as a tool for agricultural extension I Africa: a case study from Ghana. Int. J. Edu. Dev. Info. Comm. Tech. 1: 26-41.

Karubanga, G., Kibwika, P., Okry, F. and Sseguya, H. 2016. Empowering farmers to learn and innovate through integration of video and face-to-face extension approaches: The case of rice farmers in Uganda. Cogent Food Agric. 2(1): 1-12.

MacGregor, S. 2007. Sustainability through vicarious learning: reframing consumer education. Social learning towards a sustainable world. Wageningen Academic Publishers, 19: 351-402.

Tumwekwase, A. 2013. Effectiveness of video as a tool in disseminating agricultural knowledge to farmers: A case study of rice farmers in Kamwenge and Lira districts, Uganda. MSc Dissertation, Makerere University library, Uganda. pp. 60-70.

UBOS, 2010. Uganda census of agriculture 2008/2009. Volume 1. Summary report. Uganda Bureau of Statistics, Kampala, Uganda. p. 40.

Van Mele, P. 2011. Desperately seeking content: why service providers increasingly search for quality training videos. Paper presented at the international conference on innovations in extension and advisory services. Nairobi, Kenya, 15-18 November 2011. CTA. pp. 1-8.

Van Mele, P., Wanvoeke, J. and Zossou, E. 2010. Enhancing rural learning, linkages and institutions: the rice videos in Africa. Dev. Prac. 20(3): 414-421.

Van Mele, P., Zakaria, A.K.M., Begum, H., Rashid, H. and Magor, N.P. 2007. Videos that Strengthen Rural Women's Capability to Innovate. Comm. Dev. Social Change. 1(3): 65-68.

Zossou, E., Van Mele, P. Vodouhe, S.D. and Wanvoeke, J. 2010. Women Groups Formed in Response to Public Video Screenings on Rice Processing in Benin. Int. J. Agril. Sust. 8 (4): 270-277. 